\title{
Foreword
}

\section{Tribute to Tony Haymet}

It is our great pleasure to present a Special issue of Condensed Matter Physics in honour of the renowned scientist and our former scientific advisor Professor A.D.J. "Tony” Haymet, who turned 60 this February. An internationally-known physical chemist and scientific manager with over 170 scientific publications and numerous op-ed pieces, Tony Haymet served from 2006 until 2012 as the Director of the Scripps Institution of Oceanography, Vice Chancellor for Marine Sciences and Dean of the Graduate School of Marine Sciences at the University of California at San Diego (UCSD), where he is currently a Distinguished Professor.

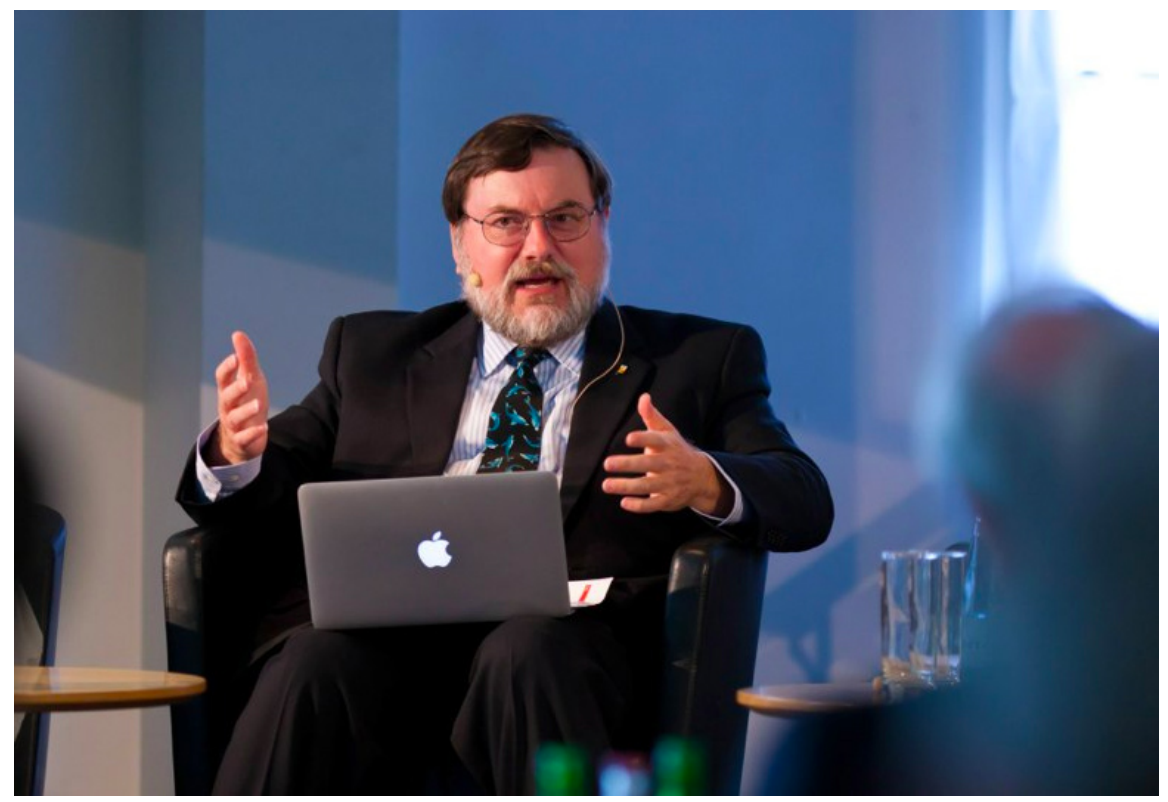

Tony Haymet speaking at Dräger Foundation conference in Sustainable Oceans: Reconciling Economic Use and Protection, July 1, 2011, Hamburg, Germany.

Born in Australia, Tony Haymet received his bachelor's degree with first class honours from University of Sydney in 1978 and moved to United States for Ph.D. studies in Chemistry at the University of Chicago. Tony started theoretical studies under scientific supervision of Professor David W. Oxtoby with the main focus on a theoretical description of thermodynamics and structure of solid-liquid interfaces. In his theoretical studies, Tony obtained an expression for effective one-body potential $C(\mathbf{r})$, which together with order parameters across the interface and density profile, allowed the estimation of interfacial free energy [1]. One of the consequences of the developed theory was a possibility to calculate the rate of solid phase nucleation in liquids. These studies resulted in his Ph.D. thesis entitled "A molecular theory of the solid-liquid interface and other properties of the liquid state" defended successfully at the University of Chicago in August 1981. In parallel with solid-liquid interfaces, Tony performed theoretical studies of pair and triplet correlations in simple liquids in collaboration with Stuart A. Rice [2].

Following graduation, Tony Haymet spent next two years as a postdoctoral research fellow at Lyman Laboratory of Physics, Harvard University. Here, Tony developed an atomic-level theory for the freezing of hard spheres [3]. Tony Haymet joined the faculty of the University of California, Berkeley, in 1983, and, 
over the next five years, further developed the density-functional theory of freezing [4,5] and solid-liquid interfaces. In addition, those years saw the launch of several new directions in Tony's research. Quantum chemical calculations for C60 and C120 complexes [6] 7] gave evidence of spherical shell molecules with the structure of Archimedean solids. In 1987, Tony began a pioneering molecular simulation work on the structure and thermodynamics of the ice-water interface [8] using the TIP4P model of water interactions. These simulations with 1440 water molecules and trajectors of up to $~ 53$ ps were quite large-scale for the time. The study of the ice-water interface through molecular simulation, ranging from the pure system [9. 11], to systems with solutes[12] or in interaction with biomolecules [13] - became definitive in Tony's scientific activities for many years to follow.

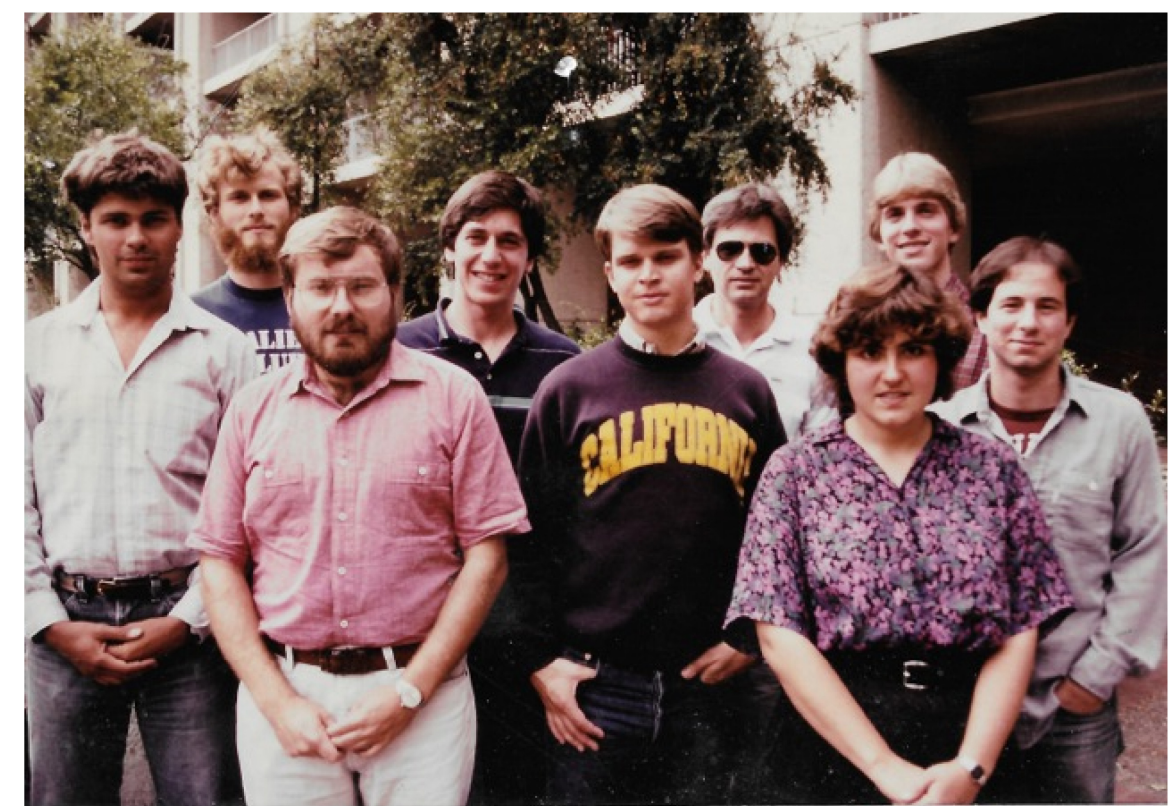

Tony's group at Berkeley, Summer 1986. From left to right: Brian Laird, Robin McCrae, Tony Haymet, Shep Smithline, Steve Rick, Vojko Vlachy, Dahlia Remler, Chris Marshall, Michael Mann.

In 1988 Tony moved to the University of Utah, where he became full professor in 1991. These years were very fruitful in theoretical and simulation exploration of ionic solutions [14 15]. It was also here that he began to delve into thinking about experimental studies of nucleation, designing the Automatic Lag Time Apparatus (or ALTA, after the famed Utah ski resort) [16]. One major focus of these experimental studies, and complimentary molecular simulations, was to understand the mechanism for nucleation in pure water and emergence of freezing potential in weak electrolyte solutions known as WorkmanReynolds effect [17.19]. In 1991 Tony Haymet returned to Australia to become Professor of Chemistry and Chair of Theoretical Chemistry at the University of Sydney. The Sydney years were marked by building the nucleation machine ALTA [20], active studies of hydrophobic effect [21,-23] and the inhibition of ice nucleation by fish antifreeze protein [24, 25]. This work formed the seed for his future trajectory in the field of marine science. Tony stayed in Sydney until 1998, when he left to become a Distinguished University Professor of Chemistry at the University of Houston (UH). There, Tony had a large scientific group of graduate students and postdoctoral fellows who performed a wide spectrum of theoretical and simulation studies on pure ice [26], water and ice-water interface [27], hydrated lipid bilayers [28] and experimental exploration of nucleation [29, 30]. During the UH years, Tony became interested in a new direction: air quality modelling - a problem which is especially important for large megapolises like Houston or Los Angeles. Those years, UH became a venue of numerous meetings on environmental problems, many of them being organized by Tony. These events highlighted Tony's skills as a modern highlevel scientific manager focused on environmental problems. These activities led to the foundation of the Environmental Modelling Institute at the University of Houston.

Late in 2002, Tony Haymet returned to Australia to be Chief of Marine Research of the CSIRO Marine 


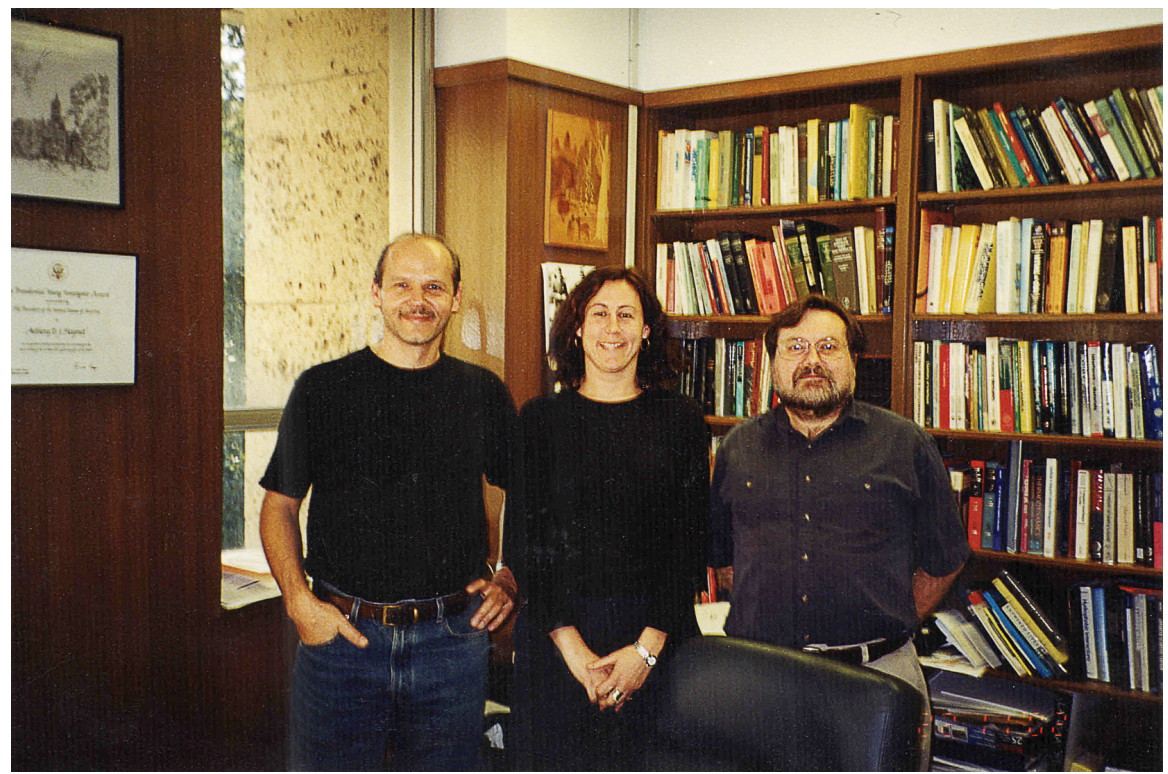

Tony Haymet in his office at the University of Houston, November 2002 - with Erica Smith and Taras Bryk.

Research Laboratory as well as Honorary Research Professor of Chemistry at the University of Tasmania in Hobart. In Australia, he was part of the founding group of the Western Australia Marine Science Institution and on the Board of Directors of CRC for Antarctic Climate and Ecosystems. Tony Haymet was appointed as Chief of CSIRO Marine and Atmospheric Research in 2006, however, soon after this appointment he accepted an offer to become the Director of Scripps Institute of Oceanography at the University of California at San Diego (UCSD).

At Scripps, in addition to leading one of the primier institutions dedicated to evironmental and marine science in the world, Tony served as the UCSD Vice Chancellor for Marine Sciences and Dean of the Graduate School of Marine Sciences, positions that he held until 2012. From his position as Director of Scripps, he became a leader in a number of regional, national and international organizations devoted to marine science, evironmental stewardship and environmental policy. He is one of the co-founders, past chair and current board member of CleanTECH San Diego, a business-oriented organization devoted to advancing a clean technology economy. During the years 2009 until 2014, he was a member, vice-chair (2013-2014), and chair (2012-2013) of the World Economic Forum's Global Agenda Council on Oceans. He has also served on the board or as advisor to a number of other organizations dedicated to marine science. He is currently a Visiting Fellow at the US Studies Centre of the University of Sydney.

This Special issue of Condensed Matter Physics contains eleven scientific papers by colleagues, friends and former research associates of Tony Haymet. Steven Rick and Brian Laird were two of Tony's graduate students during the early years at UC Berkeley. Brian Laird also joined Tony as a later postdoc at the Universities of Utah and Sydney. Also contributing are Vojko Vlachy, who was a visiting scientist in the Haymet group at Berkeley and Toshiko Ichiye - a postdoctoral associate for Tony at that time, as well. Yura Kalyuzhnyi began his collaboration with Tony as a visiting scientist to the Haymet group at the University of Utah, where Tony also began collaborations with Douglas Henderson at nearby Brigham Young University. Taras Bryk spent two productive years in Tony's group at UH. Contributions also include colleagues at the University of Houston, Monty Pettitt and Eric Bittner, as well as Peter Wilson, a former visiting scientist working with Tony at Scripps. With this issue, we all want to wish Tony a very Happy Birthday and many fruitful years in his scientific research!

Brian B. Laird (Department of Chemistry, University of Kansas, Lawrence, USA) Taras Bryk (Institute for Condensed Matter Physics of the National Academy of Sciences of Ukraine, Lviv, Ukraine; Institute of Applied Mathematics and Fundamental Sciences, Lviv Polytechnic National University, Lviv, Ukraine) 


\section{References}

1. Haymet A.D.J., Oxtoby D.W., J. Chem. Phys., 1981, 74, 2559; doi 10.1063/1.441326.

2. Haymet A.D.J., Rice S.A., Madden W.G., J. Chem. Phys., 1981, 75, 4696; doi 10.1063/1.442587.

3. Haymet A.D.J., J. Chem. Phys., 1983, 78, 4641; doi 10.1063/1.445308

4. Haymet A.D.J., Phys. Rev. Lett., 1984, 52, 1013; doi 10.1103/PhysRevLett.52.1013

5. McCoy J.D., Rick S.W., Haymet A.D.J., J. Chem. Phys., 1989, 90, 4622; doi 10.1063/1.456600

6. Haymet A.D.J., Chem. Phys. Lett., 1985, 122, 421; doi 10.1016/0009-2614(85)87239-0

7. Haymet A.D.J., J. Am. Chem. Soc., 1986, 108, 319; doi 10.1021/ja00262a035

8. Karim O.A., Haymet A.D.J., Chem. Phys. Lett., 1987, 138, 531; doi 10.1016/0009-2614(87)80118-5

9. Laird B.B., Haymet A.D.J., Chem. Rev., 1992, 92, 1819; doi 10.1021/cr00016a007

10. Hayward J.A., Haymet A.D.J., J. Chem. Phys., 2001, 114, 3713; doi 10.1063/1.1333680.

11. Bryk T., Haymet A.D.J., J. Chem. Phys., 2002, 117, 10258; doi 10.1063/1.1519538.

12. Smith E.J., Bryk T., Haymet A.D.J., J. Chem. Phys., 2005, 123, 034706; doi $10.1063 / 1.1953578$

13. Wierzbicki A., Dalal P., Cheatham T.E., Knickelbein J.E., Haymet A.D.J., Madura J.D., Biophys. J., 2007, 93, 1442; doi 10.1529/biophysj.107.105189

14. Ichiye T., Haymet A.D.J., J. Chem. Phys., 1990, 93, 8954; doi 10.1063/1.459234.

15. Kalyuzhnyi Yu.V., Holovko M.F., Haymet A.D.J., J. Chem. Phys., 1991, 95, 9151; doi 10.1063/1.461195

16. Heneghan A.F., Wilson P.W., Wang G., Haymet A.D.J., J. Chem. Phys., 2001, 115, 7599; doi 10.1063/1.1407290

17. Workman E.J., Reynolds S.E., Phys. Rev., 1950, 78, 254; doi 10.1103/PhysRev.78.254

18. Wilson P.W., Haymet A.D.J., J. Phys. Chem. B, 2008, 112, 11750; doi 10.1021/jp804047x

19. Wilson P.W., Haymet A.D.J., J. Phys. Chem. B, 2008, 112, 15260; doi 10.1021/jp807642s

20. Barlow T.W., Haymet A.D.J., Rev. Sci. Instrum., 1995, 66, 2996; doi 10.1063/1.1145586

21. Haymet A.D.J., Curr. Biol., 1999, 9, R81; doi 10.1016/S0960-9822(99)80053-0

22. Smith D.E., Haymet A.D.J., J. Chem. Phys., 1993, 98, 6445; doi 10.1063/1.464809

23. Silverstein K.A.T., Haymet A.D.J., Dill K.A., J. Am. Chem. Soc., 1998, 120, 3166; doi 10.1021/ja973029k

24. Harding M.M., Ward L.G., Haymet A.D.J., Eur. J. Biochem., 1999, 264, 653; doi 10.1046/j.1432-1327.1999.00617.x

25. Haymet A.D.J., Ward L.G., Harding M.M., J. Am. Chem. Soc., 1999, 121, 941; doi 10.1021/ja9801341

26. Gay S.C., Smith E.J., Haymet A.D.J., J. Chem. Phys., 2002, 116, 8876; doi 10.1063/1.1471556

27. Bryk T., Haymet A.D.J., Mol. Simul., 2004, 30, 131; doi $10.1080 / 0892702031000152172$

28. Ulander J., Haymet A.D.J., Biophys. J., 2003, 85, 3475; doi 10.1016/S0006-3495(03)74768-7

29. Wilson P.W., Heneghan A.F., Haymet A.D.J., Cryobiology, 2003, 46, 88; doi 10.1016/S0011-2240(02)00182-7.

30. Heneghan A.F., Moore H.J., Lee T.R., Haymet A.D.J., Chem. Phys. Lett., 2004, 385, 441; doi 10.1016/j.cplett.2004.01.025 